\title{
Efficacy of Dipterocarpus alatus oil combination with Rhinacanthus nasutus leaf and Garcinia mangostana pericarps against canine demodicosis
}

\author{
Atchara Artchayasawat ${ }^{1,2}$ (D) Parichart Boueroy ${ }^{3}$, Thidarut Boonmars ${ }^{1,2}$ (D) , Benjamabhorn Pumhirunroj4 (D), \\ Pranee Sriraj ${ }^{5}$ iD Ratchadawan Aukkanimart ${ }^{5}$ (iD, Sirintip Boonjaraspinyo ${ }^{6}$ iD, Opal Pitaksakulrat ${ }^{1}$ (iD, \\ Panaratana Ratanasuwan? (D), Apiporn Suwannatrai ${ }^{1,2}$ (D) Chatanun Eamudomkarn ${ }^{1,2}$ (D), Porntip Laummaunwai ${ }^{1}$ (i) \\ and Wu Zhiliang 8 (iD
}

1. Department of Parasitology, Faculty of Medicine, Khon Kaen University, Khon Kaen 40002, Thailand;

2. Cholangiocarcinoma Research Institute, Khon Kaen University, Khon Kaen 40002, Thailand;

3. Department of Community Health, Faculty of Public Health, Kasetsart University Chalermphrakiat Sakon Nakhon Province Campus, Sakon Nakhon 47000, Thailand; 4. Program in Animal Science, Faculty of Agricultural Technology, Sakon Nakhon Rajabhat University, Sakon Nakhon 47000, Thailand; 5. Department of Traditional Medicine, Faculty of Natural Resources, Rajamangala University of Technology ISAN Sakon Nakhon Campus, Sakon Nakhon 47160, Thailand;

6. Department of Community Medicine, Faculty of Medicine, Khon Kaen University, Khon Kaen 40002, Thailand;

7. Department of Anesthesiology, Faculty of Medicine, Khon Kaen University, Khon Kaen 40002, Thailand; 8. Department of Parasitology, Gifu University School of medicine, Gifu 501-1194, Japan.

Corresponding author: Thidarut Boonmars, e-mail: bthida@kku.ac.th

Co-authors: AA: atchara_a@kkumail.com, PB: parichart.bou@ku.th, BP: e-mail: benjamabhorn@kkumail.com, PS: srirajp11@gmail.com, RA: ratchadawan.jb@gmail.com, SB: sboon@kku.ac.th, OP: opalpi@kku.ac.th,

PR: rpana@kku.ac.th, AS: apiporn@kku.ac.th, CE: chatea@kku.ac.th, PL: porlau@kku.ac.th, WZ: wu@gifu-u.ac.jp Received: 04-07-2021, Accepted: 07-10-2021, Published online: 16-11-2021

doi: www.doi.org/10.14202/vetworld.2021.2919-2928 How to cite this article: Artchayasawat A, Boueroy P, Boonmars T, Pumhirunroj B, Sriraj P, Aukkanimart R, Boonjaraspinyo S, Pitaksakulrat O, Ratanasuwan P, Suwannatrai A, Eamudomkarn C, Laummaunwai P, Zhiliang W (2021) Efficacy of Dipterocarpus alatus oil combination with Rhinacanthus nasutus leaf and Garcinia mangostana pericarps against canine demodicosis, Veterinary World, 14(11): $2919-2928$.

Abstract

Background and Aim: Canine demodicosis is a skin disease that is a major global health problem in dogs. Ivermectin is a drug of choice for treatment, but it may cause toxicity in dogs carrying multidrug resistance mutation-1 gene mutations. Hence, alternative herbal medicines are used instead of the drug, such as Dipterocarpus alatus oil (YN oil), Rhinacanthus nasutus leaf (WC), and Garcinia mangostana pericarps (MG) extracts. This study aimed to determine the efficacy of $D$. alatus oil, $R$. nasutus leaf, and $G$. mangostana pericarp extracts on canine demodicosis in vivo.

Materials and Methods: Twenty-five mixed-breed dogs with localized demodicosis were examined. Dogs were diagnosed with demodicosis through deep skin scraping and screened with the inclusion criteria. Five dogs of each group were treated in five treatment groups (ivermectin, YN oil, YN oil+WC, YN oil+MG, and YN oil+WC+MG) for 1 month. The individual dogs were clinically evaluated, and the dermatological lesions were monitored daily for 60 days.

Results: Dermatological lesion improvement was predominantly observed in the group of dogs treated with YN oil+WC. This was evidenced by the disappearance of the hyperpigmentation and lichenification on day 28 post-treatment and alopecia on day 56 post-treatment. Moreover, no allergic or clinical signs were observed during treatment.

Conclusion: YN oil+WC is an alternative herbal medicine that could be used for the treatment of localized canine demodicosis.

Keywords: demodicosis, Dipterocarpus alatus, mangosteen pericarp, treatment, white crane flower.

\section{Introduction}

Canine demodicosis is a parasitic skin disease in dogs that occurs worldwide, including in Thailand. It is caused by the proliferation of Demodex canis in the hair follicles and sebaceous glands [1]. Nevertheless, D. canis can also cause dermatological lesions in humans [2]. Demodex spp. are detected in both humans and dogs in skin scrapings and hair samples, infestations in patients with skin complaints, and pet feeding.

Copyright: Artchayasawat, et al. Open Access. This article is distributed under the terms of the Creative Commons Attribution 4.0 International License (http://creativecommons.org/licenses/ by/4.0/), which permits unrestricted use, distribution, and reproduction in any medium, provided you give appropriate credit to the original author(s) and the source, provide a link to the Creative Commons license, and indicate if changes were made. The Creative Commons Public Domain Dedication waiver (http:// creativecommons.org/publicdomain/zero/1.0/) applies to the data made available in this article, unless otherwise stated.
There are two types of clinical demodicosis: Localized and generalized demodicosis. Ivermectin administration by mouth, injection, or absorption is an effective treatment $[3,4]$. Normally, this drug is rarely toxic, but retinopathy associated with ivermectin toxicosis in dogs has been reported [5]. A high dose is toxic in dogs carrying multidrug resistance mutation-1 gene mutations as well as the Collie breed [6].

In Thailand, the common drug for the treatment of demodicosis is ivermectin. Ivermectin is used to treat several parasites, such as helminths and arthropods. Ivermectin resistance has been reported for Dirofilaria immitis [7], Rhipicephalus sanguineus sensu stricto [8], and human Sarcoptes scabiei [9]. The most resistant are Acari mites. Demodex may be resistant to ivermectin. Moreover, in the case of secondary bacterial infection, dogs can develop pyoderma. The 
treatment comprises systemic antibiotics or topical antimicrobial therapy, such as benzoyl peroxide shampoo $(2-3 \%)$, chlorhexidine shampoo (3-4\%) [10], or ivermectin administered orally [11]. Co-administration with ketoconazole should be avoided because it could enhance the concentration of ivermectin [12].

Alternative treatments with natural compounds were shown to exhibit antimicrobial effects, efficacy, and improvement in the clinical signs of Demodex. There are various routes of administration, such as topical and oral. Natural plants and herbs have been reported, such as Azadirachta indica extract, Teeburb capsule (Berberis aristata, Cedrus deodara, Curcuma longa, and Pueraria tuberosa), and Demosymcan Gel [13-15].

Thus, this study was conducted to use natural compounds from Dipterocarpus alatus, Rhinacanthus nasutus, and Garcinia mangostana. D. alatus is a tropical forest tree that is commonly found in Southeast Asia. Dipterocarpol derivatives have anti-inflammatory, antiviral, and immunostimulation effects [16-18]. The oil from D. alatus (YN oil) was investigated. An individual tree can yield $0.5 \mathrm{~L} /$ day. The average price of $\mathrm{YN}$ oil on the local market is currently $228 \mathrm{Baht} / \mathrm{kg}$ (\$7.00) with a range of 170-286 $\mathrm{Baht} / \mathrm{kg}$ (\$5.22-\$8.78).

$R$. nasutus is a medicinal herb. Its common name is white crane flower (WC), and it is also found in Southeast Asia. WC can easily be propagated by stem cuttings. It has antioxidant and anti-inflammatory effects $[19,20]$. G. mangostana, also known as mangosteen (MG), is a tropical fruit found in Southeast Asia. It has antioxidant, antiparasitic, and anticancer effects [21-23].

This study aimed to determine the efficiency of YN oil, WC, and MG against canine demodicosis using a possible topical treatment.

\section{Materials and Methods}

\section{Ethical approval and Informed consent}

The study was approved by the Khon Kaen University Animal Ethics Committee (ACUC-KKU-19/2559). A consent form was signed by the dogs' owners before the examinations. In brief, the dog's history was taken, and a general physical examination was done. Dogs presenting with Demodex lesions were recorded. Dogs were fed normal food from the dogs' owners and one boiled egg per day for 30 days. The boiled egg was used to control food intake from the diet. All dogs were bathed with WC shampoo (Neocare shampoo ${ }^{\circledR}$, Vechmart, Thailand) every week for the prevention and control of Malassezia pachydermatis by the research team according to the manufacturer's instructions. In the case of a cure rate $<50 \%$, the dog was treated with ivermectin after the end of the experiment within 2 months.

\section{Study period and location}

The study was conducted from July to November 2018. The study was conducted in a village of Sakon Nakhon Province, Northeast Thailand $\left(17^{\circ} 22^{\prime} 25.2^{\prime \prime} \mathrm{N}\right.$, $103^{\circ} 43^{\prime} 12.9^{\prime \prime} \mathrm{E}$ ).

\section{Canine demodicosis}

Twenty-five dogs (males and females) with demodicosis, aged 5-120 months, and with body weight of 7-20 kg, were used in the experiment, as shown in Figure-1. Dogs with skin lesions were confirmed to have demodicosis by deep skin scraping. The criteria for localized demodicosis were the following: (i) No more than four lesions with a diameter of up to $2.5 \mathrm{~cm} \mathrm{[24]} \mathrm{and} \mathrm{(ii)} \mathrm{a} \mathrm{range} \mathrm{of} \mathrm{four}$ lesions to $50 \%$ coverage of the body surface with lesions [3].
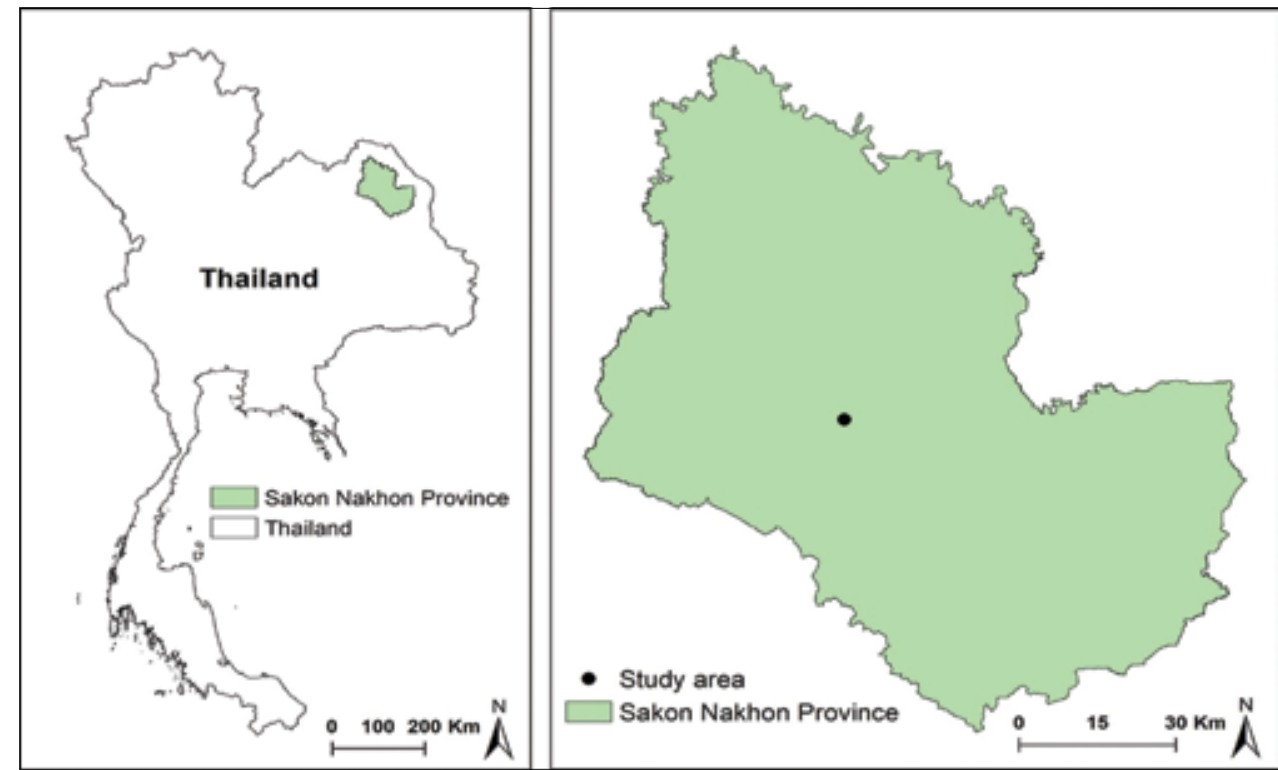

Figure-1: The location of the village in Phang Khon District, Sakon Nakhon Province, Northeast Thailand [Source: The administrative boundaries of Sakon Nakon Province and Thailand were downloaded from the DIVA-GIS database (http:// www.diva-gis.org). A geographical information system (GIS) software ArcGIS 10.8 (ESRI, Redlands CA) was used to create a study map]. 
The inclusion criteria for the canine demodicosis participants were as follows: (i) Age of more than 8 weeks, (ii) the presence of Demodex mites in skin scraping (Figure-2), (iii) clinically healthy except for clinical signs associated with localized demodicosis, (iv) no pregnancy history, and (v) no glucocorticoid treatment or any acaricide for at least 12 weeks before day 0 . Dogs whose data could not be recorded until the end of the experiment were excluded from the study [25].

\section{Plant materials and preparation}

YN oil was provided by Dr. Somporn Katekaew from the Faculty of Sciences, Khon Kaen University. The oil was collected from the stem of the tree. Briefly, the trees were drilled with holes, and then a container was used to collect oil from the holes. Chemical compositions were characterized by Asst. Prof. Dr. Ploenthip Puthongking from the Faculty of Pharmaceutical Sciences, Khon Kaen University [26]. The oil was melted in a beaker on a hotplate for $10 \mathrm{~min}$ at $60^{\circ} \mathrm{C}$. Then, $60 \% \mathrm{YN}$ oil in distilled water was prepared using a stand mixer for at least $30 \mathrm{~min}$ at $25^{\circ} \mathrm{C}$.

WC was purchased from a local market in Khon Kaen Province and then extracted using a modified methanolic extract method [27]. Briefly, $500 \mathrm{~g}$ of fresh leaves were macerated with $1000 \mathrm{~mL}$ of ethanol at room temperature for 7 days. The macerate was filtered through $0.45 \mu \mathrm{m}$ filter paper and evaporated using a rotary evaporator to remove the solvent. Then, $1.36 \% \mathrm{w} / \mathrm{v} \mathrm{WC}$ was dissolved in distilled water and mixed well for at least $30 \mathrm{~min}$ at $25^{\circ} \mathrm{C}$.

MG was purchased from a local market. MG extracts were prepared as in our previous study [22]. Briefly, fresh $M G$ pericarps were incubated at $60^{\circ} \mathrm{C}$, and then, the dried MG pericarps were macerated with ethanol at room temperature for 3 weeks. The macerate was filtered and evaporated. Subsequently, $10 \% \mathrm{w} / \mathrm{v}$ MG was dissolved in 4\% dimethyl sulfoxide and mixed well for at least $30 \mathrm{~min}$ at $25^{\circ} \mathrm{C}$. All preparations were kept in a refrigerator at $4^{\circ} \mathrm{C}$. The $\mathrm{YN}$ oil, $\mathrm{YN}$ oil $+\mathrm{WC}$, YN oil $+\mathrm{MG}$, and $\mathrm{YN}$ oil $+\mathrm{WC}+\mathrm{MG}$ had a $\mathrm{pH}$ of 5.

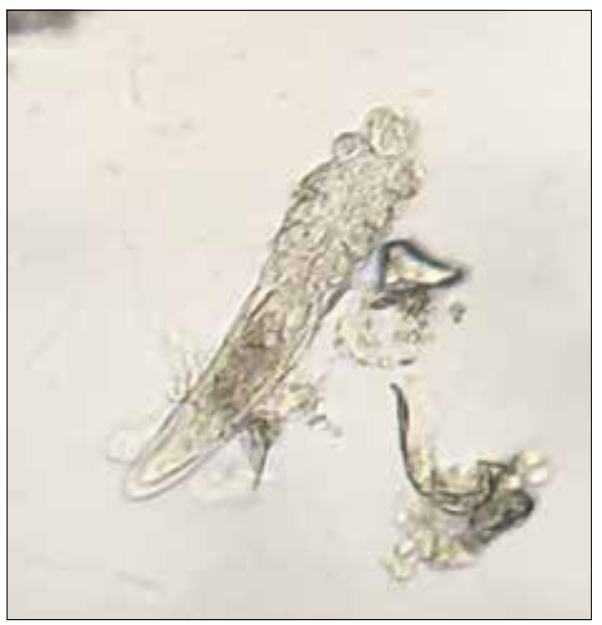

Figure-2: Demodex mites diagnosed with deep skin scraping.

\section{Determination of components}

YN oil was tested with a gas chromatograph-mass spectrometer [26]. The major components of the YN oil are sesquiterpenes, including $\alpha$-gurjunene (30.31\%), $(-)$-isoledene $(13.69 \%)$, alloaromadendrene $(3.28 \%)$, $\beta$-caryophyllene $(3.14 \%), \gamma$-gurjunene $(3.14 \%)$, and spathulenol $(1.11 \%)$. The presence of components was confirmed using thin-layer chromatography. This method was used for fingerprint analysis of the WC and $\mathrm{MG}$ extracts according to the previous studies before using them [23,28].

\section{Antioxidant activity determination}

We confirmed the antioxidant activity of YN oil, MG, and WC. Free-radical scavenging activity was tested by 2,2-diphenyl-1-picrylhydrazyl (DPPH; Sigma-Aldrich, USA). The DPPH assay was modified from Aksoy et al. [29]. Briefly, the test samples were $100 \mu \mathrm{L}$ of extracts (YN oil, MG, or WC) or a standard antioxidant compound ( \pm )-6-hydroxy-2,5,7,8-tetramethylchromane-2-carboxylic acid (Trolox; Sigma-Aldrich, USA). The samples had various concentrations in $100 \mu \mathrm{L}$ of the ethanolic DPPH • solution. Furthermore, $100 \mu \mathrm{L}$ of ethanol and $100 \mu \mathrm{L}$ of ethanolic DPPH• solution were used as a control. The solutions were incubated for $30 \mathrm{~min}$ at room temperature. The absorbance values were determined using a microplate reader (Sunrise ${ }^{\mathrm{TM}}$, Austria). The absorbances were measured at $540 \mathrm{~nm}$. The antiradical activity was calculated as the inhibition percentage (I\%) using the following equation:

$(\mathrm{I} \%)=($ absorbance control - absorbance sample $) /$ absorbance control $\times 100$

We also calculated the half-maximal inhibitory concentration $\left(\mathrm{IC}_{50}\right)$ value, which is the concentration of the extracts that caused $50 \%$ inhibition. The I\% was plotted for five concentrations of extracts to obtain inhibition curves. A regression equation was estimated from the absorbance data points as follows:

$\mathrm{I}=\mathrm{mc}+\mathrm{k}$

Where I is the I\%; c indicates the concentration of YN oil, MG, or WC extract or Trolox; $m$ is the slope; and $\mathrm{k}$ is the intercept. $\mathrm{The}_{\mathrm{IC}}$ values of Trolox, WC, and MG extracts were estimated to be 14.13, 174.27 , and $84.38 \mu \mathrm{g} / \mathrm{mL}$, respectively. However, the $\mathrm{IC}_{50}$ of $\mathrm{YN}$ oil suggested no antioxidant activity. The best result among the herbal treatments was observed for the MG extracts.

Efficacy of $D$. alatus oil on canine demodicosis in vivo A total of 25 dogs were divided into five treatment groups (five dogs/group): (i) A positive control (PC) group that received $10 \mathrm{mg} / \mathrm{mL}$ of ivermectin (Ivome $^{\mathrm{c} \mathbb{R}}$, Merial Saude Animal Ltda, Brazil), (ii) dogs treated with topical YN oil, (iii) dogs treated with topical YN oil+WC, (iv) dogs treated with topical YN 
oil $+\mathrm{MG}$, and (v) dogs treated with topical $\mathrm{YN}$ oil $+\mathrm{W}-$ $\mathrm{C}+\mathrm{MG}$ (Table-1). All dogs were shaved in the lesion areas. The fingertip unit of each treatment was applied to the skin lesions 3 times/week for 1 month. The dogs were photographed every day for 2 months. Pre-treatment photographs were taken at baseline, and post-treatment photographs were taken at the end of treatment for comparison. A skin scraping was not performed at the end of treatment.

\section{Clinical evaluation}

The specific clinical parameters evaluated were alopecia, hyperpigmentation, and lichenification. The demodectic lesions on each dog were recorded, as shown in Table-2. In this table, the overall resolution of lesions is presented. Note that not all demodectic lesions were found on each dog.

Alopecia was assessed as follows: 0, no alopecia (hair regrowth); 1 , alopecia areas with partial hair regrowth; and 2, alopecia areas with no hair regrowth (Table-3) [30]. Hyperpigmentation and lichenification were assessed as follows: 0, no lesions (absent), and 1 , lesion observed (Table-4). The efficacy evaluation was based on the percentage of reduction in dermatological changes on a dog after treatment. The numbers of dogs in a group affected by alopecia, hyperpigmentation, and lichenification were compared between pre-treatment and post-treatment.

\section{Health observations}

To evaluate the overall health, other clinical signs during treatment were recorded for all dogs, including allergy, lack of appetite, and lethargy.

\section{Statistical analysis}

Cochran's Q test was used to compare the dermatological changes of different time points for

Table-1: Treatment application and concentration for each experimental group.

\begin{tabular}{|c|c|c|}
\hline Groups & Concentration & Application \\
\hline mectin) & $400 \mu \mathrm{g} / \mathrm{kg}$ & $\begin{array}{l}\text { Subcutaneous } \\
\text { injection, once a } \\
\text { month }\end{array}$ \\
\hline ii YN oil & $60 \%$ YN oil in DW & $\begin{array}{l}\text { Topical treatment, } \\
3 \text { times a week }\end{array}$ \\
\hline iii YN oil+WC & $\begin{array}{l}60 \% \text { YN oil and } \\
1.36 \% \mathrm{w} / \mathrm{v} \text { WC in DW }\end{array}$ & $\begin{array}{l}\text { Topical treatment, } \\
3 \text { times a week }\end{array}$ \\
\hline iv YN oil+MG & $\begin{array}{l}60 \% \text { YN oil with } 10 \% \\
\text { w/v MG in } 4 \% \text { DMSO }\end{array}$ & $\begin{array}{l}\text { Topical treatment, } \\
3 \text { times a week }\end{array}$ \\
\hline v YN oil+WC+MG & $\begin{array}{l}60 \% \text { YN oil, } 1.36 \% \\
\text { w/v WC, and } 10 \% \\
\text { w/v MG in } 4 \% \text { DMSO }\end{array}$ & $\begin{array}{l}\text { Topical treatment, } \\
3 \text { times a week }\end{array}$ \\
\hline
\end{tabular}

YN oil=Dipterocarpus alatus oil, WC $=$ Rhinacanthus nasutus leaf, $\mathrm{MG}=$ Garcinia mangostana pericarps, $\mathrm{PC}=$ Positive control

Table-2: Percentage of dermatological lesions on dogs.

\begin{tabular}{lc}
\hline $\begin{array}{l}\text { Dermatological } \\
\text { lesions }\end{array}$ & $\begin{array}{c}\text { Number of dermatological lesion } \\
\text { dogs/Total number of dogs (\%) }\end{array}$ \\
\hline Alopecia & $25 / 25(100)$ \\
Hyperpigmentation & $20 / 25(80)$ \\
Lichenification & $22 / 25(88)$ \\
\hline
\end{tabular}

each treatment. A value of $\mathrm{p}<0.05$ was considered statistically significant.

\section{Results}

\section{General appearance}

In Table-2, alopecia, hyperpigmentation, and lichenification were observed in $25(100 \%), 20(80 \%)$, and $22(88 \%)$ dogs, respectively.

\section{Effect of $D$. alatus oil on clinical signs}

Clinical improvement was evident in dogs treated with YN oil+WC, including hair regrowth and reduced signs of hyperpigmentation and lichenification. The dermatological lesions were gradually reduced, and normal hair regrowth was observed at 14 days post-treatment with YN oil and YN oil+WC. On day 56, alopecia in all treatment groups significantly decreased $(\mathrm{p}<0.01)$. The PC treatment seemed to be effective, but $20 \%$ of the PC group presented with alopecia. By contrast, alopecia completely disappeared in dogs treated with YN oil and $\mathrm{YN}$ oil+WC (Table-5 and Figures-3-7).

Hyperpigmentation was reduced by $50 \%$ after 21 days post-treatment with $\mathrm{YN}$ oil+WC. On day 28, dogs in the $\mathrm{YN}$ oil $+\mathrm{WC}$ group presented with $0 \%$ hyperpigmentation $(\mathrm{p}<0.01)$, whereas the treated dogs in the YN oil group showed $0 \%$ hyperpigmentation on day $56(\mathrm{p}<0.01)$. Hyperpigmentation was present in $25 \%$ of dogs in the PC and $\mathrm{YN}$ oil $+\mathrm{WC}+\mathrm{MG}$ groups $(p<0.05$ and $p<0.01$, respectively). No statistically significant difference $(p>0.05)$ was observed in dogs treated with YN oil+MG.

Lichenification lesions of dogs treated with YN oil $+\mathrm{WC}+\mathrm{MG}$ and $\mathrm{YN}$ oil $+\mathrm{WC}$ were reduced by $20 \%$ and $40 \%$ after 21 days post-treatment, respectively. The $\mathrm{YN}$ oil $+\mathrm{WC}+\mathrm{MG}$ and $\mathrm{YN}$ oil $+\mathrm{WC}$ groups showed a $100 \%$ total reduction in lichenification on day 28 $(\mathrm{p}<0.001)$. On day 56, dogs treated with YN oil and the PC group showed $0 \%$ and $25 \%$ reductions, respectively $(\mathrm{p}<0.05)$. No statistically significant difference $(p>0.05)$ was observed in the $\mathrm{YN}$ oil $+\mathrm{MG}$ group.

\section{Health observations}

After 2 months of observation, no allergy or clinical signs were observed on the skin, in behavior, or on the body.

\section{Discussion}

YN oil, WC, and MG are very popular alternative herbal medicines as treatments for antibacterial effects, antifungal effects, liver diseases, and rheumatism. To the best of our knowledge, this study is the first to show that $\mathrm{YN}$ oil+WC is useful for localized canine demodicosis in dogs, with a focus on hair regrowth and the disappearance of hyperpigmentation and lichenification. The dermatological lesions were not detectable in dogs on day 56 post-treatment. Moreover, dogs treated with YN oil, YN oil $+\mathrm{MG}$, and $\mathrm{YN}$ oil $+\mathrm{WC}+\mathrm{MG}$ showed reduced dermatological lesions. No allergic or clinical signs were observed during treatment. The treatments were used 3 times/week for 1 month. Together with a 
Table-3: Clinical score of alopecia in all dog groups.

\begin{tabular}{|c|c|c|c|c|c|c|c|c|}
\hline \multirow[t]{2}{*}{ Clinical sign } & \multirow[t]{2}{*}{ Groups } & \multirow[t]{2}{*}{ Score } & \multicolumn{6}{|c|}{ Number of dogs per score/Number of dogs examined } \\
\hline & & & Day 0 & Day 7 & Day 14 & Day 21 & Day 28 & Day 56 \\
\hline \multirow{15}{*}{ Alopecia } & i PC & 0 & $0 / 5$ & $0 / 5$ & $0 / 5$ & $2 / 5$ & $2 / 5$ & $4 / 5$ \\
\hline & & 1 & $0 / 5$ & $2 / 5$ & $4 / 5$ & $3 / 5$ & $3 / 5$ & $1 / 5$ \\
\hline & & 2 & $5 / 5$ & $3 / 5$ & $1 / 5$ & $0 / 5$ & $0 / 5$ & $0 / 5$ \\
\hline & ii YN oil & 0 & $0 / 5$ & $0 / 5$ & $1 / 5$ & $1 / 5$ & $4 / 5$ & $5 / 5$ \\
\hline & & 1 & $0 / 5$ & $4 / 5$ & $3 / 5$ & $4 / 5$ & $1 / 5$ & $0 / 5$ \\
\hline & & 2 & $5 / 5$ & $1 / 5$ & $1 / 5$ & $0 / 5$ & $0 / 5$ & $0 / 5$ \\
\hline & iii YN oil+WC & 0 & $0 / 5$ & $0 / 5$ & $1 / 5$ & $2 / 5$ & $4 / 5$ & $5 / 5$ \\
\hline & & 1 & $0 / 5$ & $4 / 5$ & $4 / 5$ & $3 / 5$ & $1 / 5$ & $0 / 5$ \\
\hline & & 2 & $5 / 5$ & $1 / 5$ & $0 / 5$ & $0 / 5$ & $0 / 5$ & $0 / 5$ \\
\hline & iv YN oil+MG & 0 & $0 / 5$ & $0 / 5$ & $0 / 5$ & $1 / 5$ & $3 / 5$ & $4 / 5$ \\
\hline & & 1 & $0 / 5$ & $3 / 5$ & $4 / 5$ & $3 / 5$ & $2 / 5$ & $1 / 5$ \\
\hline & & 2 & $5 / 5$ & $2 / 5$ & $1 / 5$ & $1 / 5$ & $0 / 5$ & $0 / 5$ \\
\hline & v YN oil+WC+MG & 0 & $0 / 5$ & $0 / 5$ & $0 / 5$ & $0 / 5$ & $4 / 5$ & $4 / 5$ \\
\hline & & 1 & $0 / 5$ & $4 / 5$ & $4 / 5$ & $4 / 5$ & $1 / 5$ & $1 / 5$ \\
\hline & & 2 & $5 / 5$ & $1 / 5$ & $1 / 5$ & $1 / 5$ & $0 / 5$ & $0 / 5$ \\
\hline
\end{tabular}

$0=$ No alopecia (hair regrowth), $1=$ Alopecia areas with partial hair regrowth, $2=$ Alopecia areas with no hair re-growth. YN oil=Dipterocarpus alatus oil, WC=Rhinacanthus nasutus leaf, MG=Garcinia mangostana pericarps, PC=Positive control

Table-4: Clinical score of hyperpigmentation and lichenification in all dog groups.

\begin{tabular}{|c|c|c|c|c|c|c|c|c|}
\hline \multirow[t]{2}{*}{ Clinical sign } & \multirow[t]{2}{*}{ Groups } & \multirow[t]{2}{*}{ Score } & \multicolumn{6}{|c|}{ Number of dogs per score/Number of dogs examined } \\
\hline & & & Day 0 & Day 7 & Day 14 & Day 21 & Day 28 & Day 56 \\
\hline \multirow[t]{10}{*}{ Hyperpigmentation } & i PC & 0 & $0 / 4$ & $0 / 4$ & $0 / 4$ & $0 / 4$ & $1 / 4$ & $3 / 4$ \\
\hline & & 1 & $4 / 4$ & $4 / 4$ & $4 / 4$ & $4 / 4$ & $3 / 4$ & $1 / 4$ \\
\hline & ii YN oil & 0 & $0 / 4$ & $0 / 4$ & $0 / 4$ & $0 / 4$ & $2 / 4$ & $4 / 4$ \\
\hline & & 1 & $4 / 4$ & $4 / 4$ & $4 / 4$ & $4 / 4$ & $2 / 4$ & $0 / 4$ \\
\hline & iii YN oil+WC & 0 & $0 / 4$ & $0 / 4$ & $0 / 4$ & $2 / 4$ & $4 / 4$ & $4 / 4$ \\
\hline & & 1 & $4 / 4$ & $4 / 4$ & $4 / 4$ & $2 / 4$ & $0 / 4$ & $0 / 4$ \\
\hline & iv YN oil+MG & 0 & $0 / 4$ & $0 / 4$ & $0 / 4$ & $0 / 4$ & $1 / 4$ & $2 / 4$ \\
\hline & & 1 & $4 / 4$ & $4 / 4$ & $4 / 4$ & $4 / 4$ & $3 / 4$ & $2 / 4$ \\
\hline & v YN oil+WC+MG & 0 & $0 / 4$ & $0 / 4$ & $0 / 4$ & $0 / 4$ & $3 / 4$ & $3 / 4$ \\
\hline & & 1 & $4 / 4$ & $4 / 4$ & $4 / 4$ & $4 / 4$ & $1 / 4$ & $1 / 4$ \\
\hline \multirow[t]{10}{*}{ Lichenification } & i PC & 0 & $0 / 4$ & $0 / 4$ & $0 / 4$ & $0 / 4$ & $1 / 4$ & $3 / 4$ \\
\hline & & 1 & $4 / 4$ & $4 / 4$ & $4 / 4$ & $4 / 4$ & $3 / 4$ & $1 / 4$ \\
\hline & ii YN oil & 0 & $0 / 3$ & $0 / 3$ & $0 / 3$ & $0 / 3$ & $2 / 3$ & $3 / 3$ \\
\hline & & 1 & $3 / 3$ & $3 / 3$ & $3 / 3$ & $3 / 3$ & $1 / 3$ & $0 / 3$ \\
\hline & iii YN oil+WC & 0 & $0 / 5$ & $0 / 5$ & $0 / 5$ & $2 / 5$ & $5 / 5$ & $5 / 5$ \\
\hline & & 1 & $5 / 5$ & $5 / 5$ & $5 / 5$ & $3 / 5$ & $0 / 5$ & $0 / 5$ \\
\hline & iv $Y N$ oil+MG & 0 & $0 / 5$ & $0 / 5$ & $0 / 5$ & $1 / 5$ & $2 / 5$ & $3 / 5$ \\
\hline & & 1 & $5 / 5$ & $5 / 5$ & $5 / 5$ & $4 / 5$ & $3 / 5$ & $2 / 5$ \\
\hline & v YN oil+WC+MG & 0 & $0 / 5$ & $0 / 5$ & $0 / 5$ & $1 / 5$ & $5 / 5$ & $5 / 5$ \\
\hline & & 1 & $5 / 5$ & $5 / 5$ & $5 / 5$ & $4 / 5$ & $0 / 5$ & $0 / 5$ \\
\hline
\end{tabular}

$0=$ No lesions (absent); $1=$ Lesion observed. YN oil=Dipterocarpus alatus oil, WC=Rhinacanthus nasutus leaf, MG=Garcinia mangostana pericarps, $\mathrm{PC}=$ Positive control

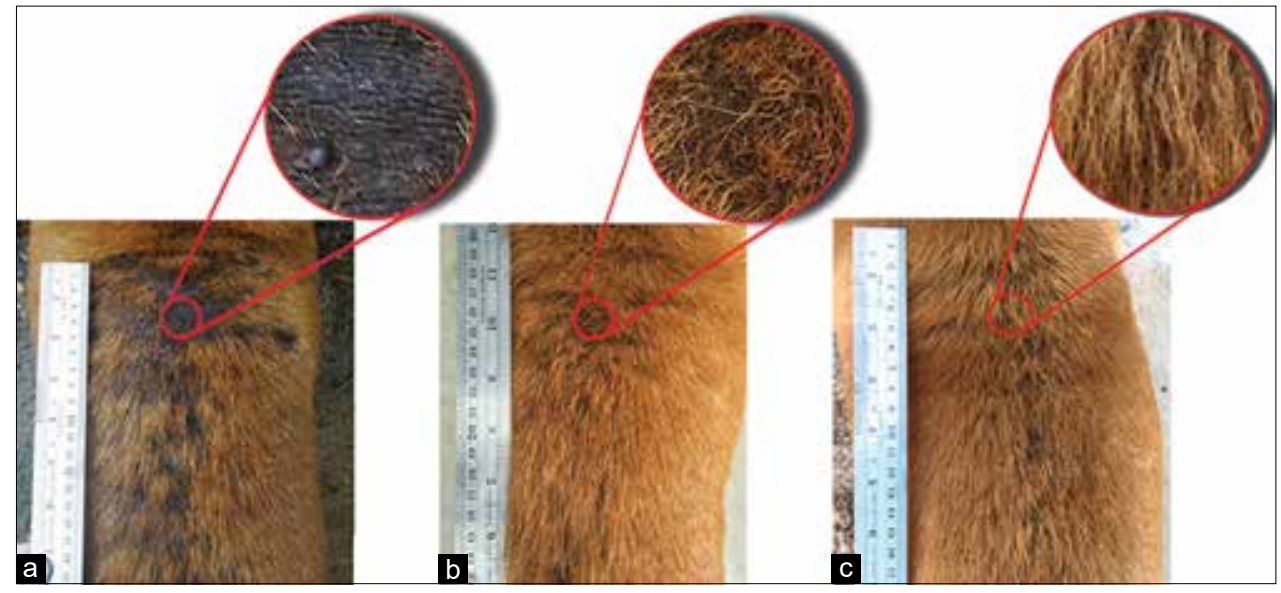

Figure-3: Occurrence of lesions in pre- and post-treatment of the positive control group. Back part; pre-treatment (a), 28 days post-treatment (b), and 74 days post-treatment (c). 
Table-5: Percentage of reduction of dermatologic changes on the dogs after treatment (number of dogs/number of dogs per group).

\begin{tabular}{|c|c|c|c|c|c|c|c|c|}
\hline Clinical sign & Groups & Day 0 & Day 7 & Day 14 & Day 21 & Day 28 & Day 56 & p-value \\
\hline \multirow[t]{5}{*}{ Alopecia } & i PC & $100 \%(5 / 5)$ & $100 \%(5 / 5)$ & $100 \%(5 / 5)$ & $100 \%(5 / 5)$ & $60 \%(3 / 5)$ & $20 \%(1 / 5)$ & $<0.01$ \\
\hline & ii YN oil & $100 \%(5 / 5)$ & $100 \%(5 / 5)$ & $80 \%(4 / 5)$ & $80 \%(4 / 5)$ & $20 \%(1 / 5)$ & $0 \%(0 / 5)$ & $<0.01$ \\
\hline & iii YN oil+WC & $100 \%(5 / 5)$ & $100 \%(5 / 5)$ & $80 \%(4 / 5)$ & $60 \%(3 / 5)$ & $20 \%(1 / 5)$ & $0 \%(0 / 5)$ & $<0.01$ \\
\hline & iv $Y N$ oil+MG & $100 \%(5 / 5)$ & $100 \%(5 / 5)$ & $100 \%(5 / 5)$ & $80 \%(4 / 5)$ & $40 \%(2 / 5)$ & $20 \%(1 / 5)$ & $<0.01$ \\
\hline & v YN oil+WC+MG & $100 \%(5 / 5)$ & $100 \%(5 / 5)$ & $100 \%(5 / 5)$ & $100 \%(5 / 5)$ & $20 \%(1 / 5)$ & $20 \%(1 / 5)$ & $<0.01$ \\
\hline \multirow[t]{5}{*}{ Hyperpigmentation } & i PC & $100 \%(4 / 4)$ & $100 \%(4 / 4)$ & $100 \%(4 / 4)$ & $100 \%(4 / 4)$ & $75 \%(3 / 4)$ & $25 \%(1 / 4)$ & $<0.05$ \\
\hline & ii YN oil & $100 \%(4 / 4)$ & $100 \%(4 / 4)$ & $100 \%(4 / 4)$ & $100 \%(4 / 4)$ & $50 \%(2 / 4)$ & $0 \%(0 / 4)$ & $<0.01$ \\
\hline & iii YN oil+WC & $100 \%(4 / 4)$ & $100 \%(4 / 4)$ & $100 \%(4 / 4)$ & $50 \%(2 / 4)$ & $0 \%(0 / 4)$ &  & $<0.01$ \\
\hline & iv $Y N$ oil+MG & $100 \%(4 / 4)$ & $100 \%(4 / 4)$ & $100 \%(4 / 4)$ & $100 \%(4 / 4)$ & $75 \%(3 / 4)$ & $50 \%(2 / 4)$ & $>0.05$ \\
\hline & v YN oil+WC+MG & $100 \%(4 / 4)$ & $100 \%(4 / 4)$ & $100 \%(4 / 4)$ & $100 \%(4 / 4)$ & $25 \%(1 / 4)$ & $25 \%(1 / 4)$ & $<0.01$ \\
\hline \multirow[t]{5}{*}{ Lichenification } & i PC & $100 \%(4 / 4)$ & $100 \%(4 / 4)$ & $100 \%(4 / 4)$ & $100 \%(4 / 4)$ & $75 \%(3 / 4)$ & $25 \%(1 / 4)$ & $<0.05$ \\
\hline & ii YN oil & $100 \%(3 / 3)$ & $100 \%(3 / 3)$ & $100 \%(3 / 3)$ & $100 \%(3 / 3)$ & $33 \%(1 / 3)$ & $0 \%(0 / 3)$ & $<0.05$ \\
\hline & iii YN oil+WC & $100 \%(5 / 5)$ & $100 \%(5 / 5)$ & $100 \%(5 / 5)$ & $60 \%(3 / 5)$ & $0 \%(0 / 5)$ & - & $<0.001$ \\
\hline & iv $Y N$ oil+MG & $100 \%(5 / 5)$ & $100 \%(5 / 5)$ & $100 \%(5 / 5)$ & $80 \%(4 / 5)$ & $60 \%(3 / 5)$ & $40 \%(2 / 5)$ & $>0.05$ \\
\hline & v YN oil+WC+MG & $100 \%(5 / 5)$ & $100 \%(5 / 5)$ & $100 \%(5 / 5)$ & $80 \%(4 / 5)$ & $0 \%(0 / 5)$ & - & $<0.001$ \\
\hline
\end{tabular}

Group i $(P C)=$ Dogs treated with ivermectin; Group ii (YN oil)=Dogs treated with topical YN oil;

Group iii $(Y N$ oil+WC)=Dogs treated with topical YN oil+WC; Group iv (YN oil+MG)=Dogs treated with topical YN oil+MG; Group $\vee(Y N$ oil+WC+MG)=Dogs treated with topical $Y N$ oil+WC+MG. $P<0.05$ was considered significant.

YN oil=Dipterocarpus alatus oil, WC=Rhinacanthus nasutus leaf, MG=Garcinia mangostana pericarps, PC=Positive control



Figure-4: Occurrence of lesions in pre- and post-treatment of the YN oil group. Back part; pre-treatment (a), after shaving (b), 25 days post-treatment (c), and 56 days post-treatment (d).

WC, the shampoo was used for fungal prevention once per week.

Ivermectin is a common first choice for demodicosis treatment [31]. This drug acts as agamma-aminobutyric acid receptor agonist in the nerve cells of Demodex, resulting in parasite paralysis and death [32]. In the present study, the efficacy of the single dose of ivermectin injection was less than that of the alternative herbal medication of localized demodicosis treatment as evidenced by the dermatological lesions post-treatment (Table-5). A decrease in the overall dermatological lesions was noted, but there were still $20 \%$ alopecia, $25 \%$ hyperpigmentation, and $25 \%$ lichenification on day 56 post-treatment. By contrast, our present research shows success in 100\% of three dermatological lesions curative with $\mathrm{YN}+\mathrm{WC}$ treatment in dogs on day 56 post-treatment.

A previous study has shown that there are some herbal medicines for canine demodicosis. Herbal medicines are useful in the treatment of canine demodicosis using oral Teeburb capsules and the local application of skin healing spray [15]. Withania somnifera extract can be used for the treatment of canine demodicosis through antioxidant activity [33]. Nevertheless, there has been no report of the three herbs in this study for the treatment of canine demodicosis. They are not known to have miticidal properties, although there have been reports on their various properties. The clinical 


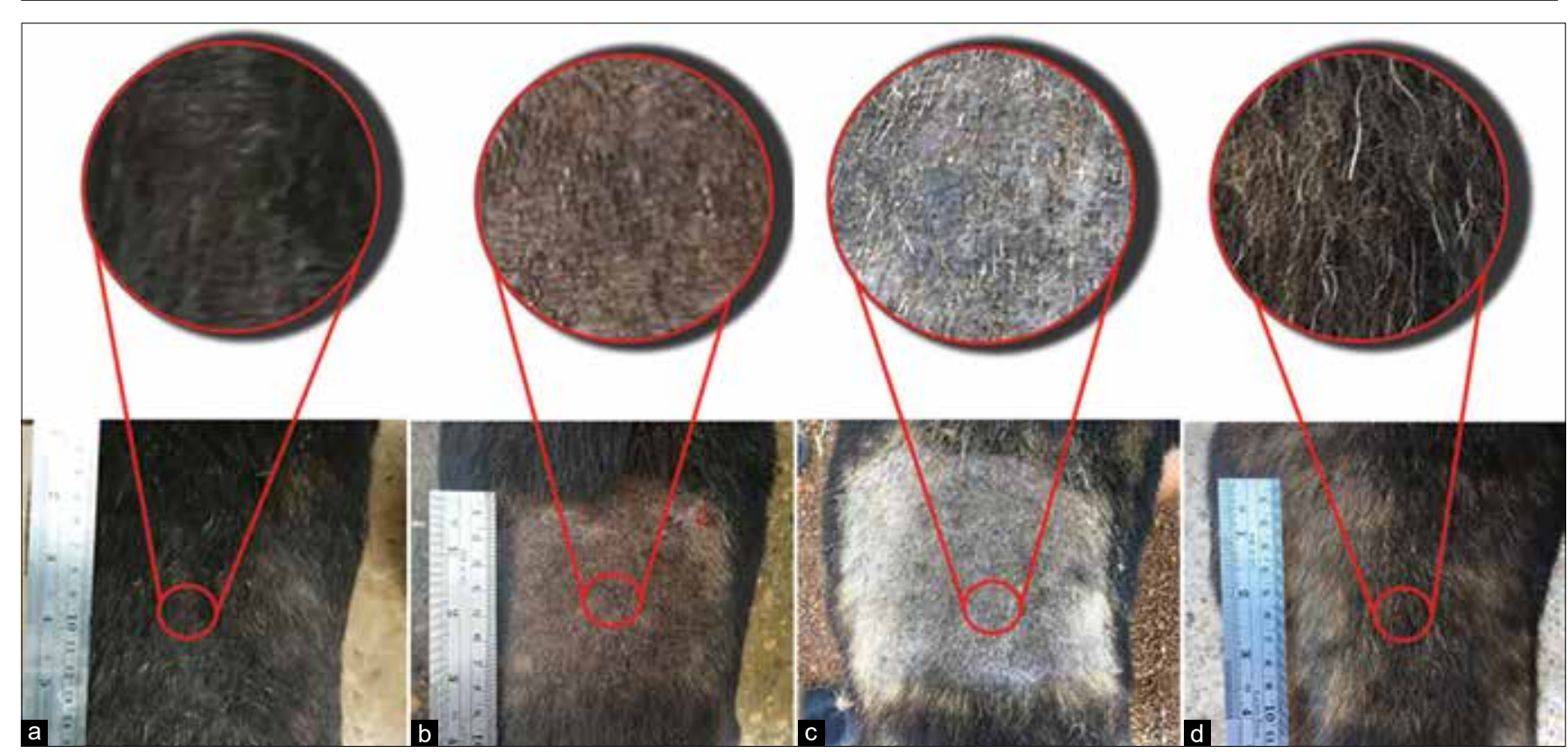

Figure-5: Occurrence of lesions in pre- and post-treatment of YN oil+WC group. Back part; pre-treatment (a), after shaving (b), 25 days post-treatment (c), and 56 days post-treatment (d).

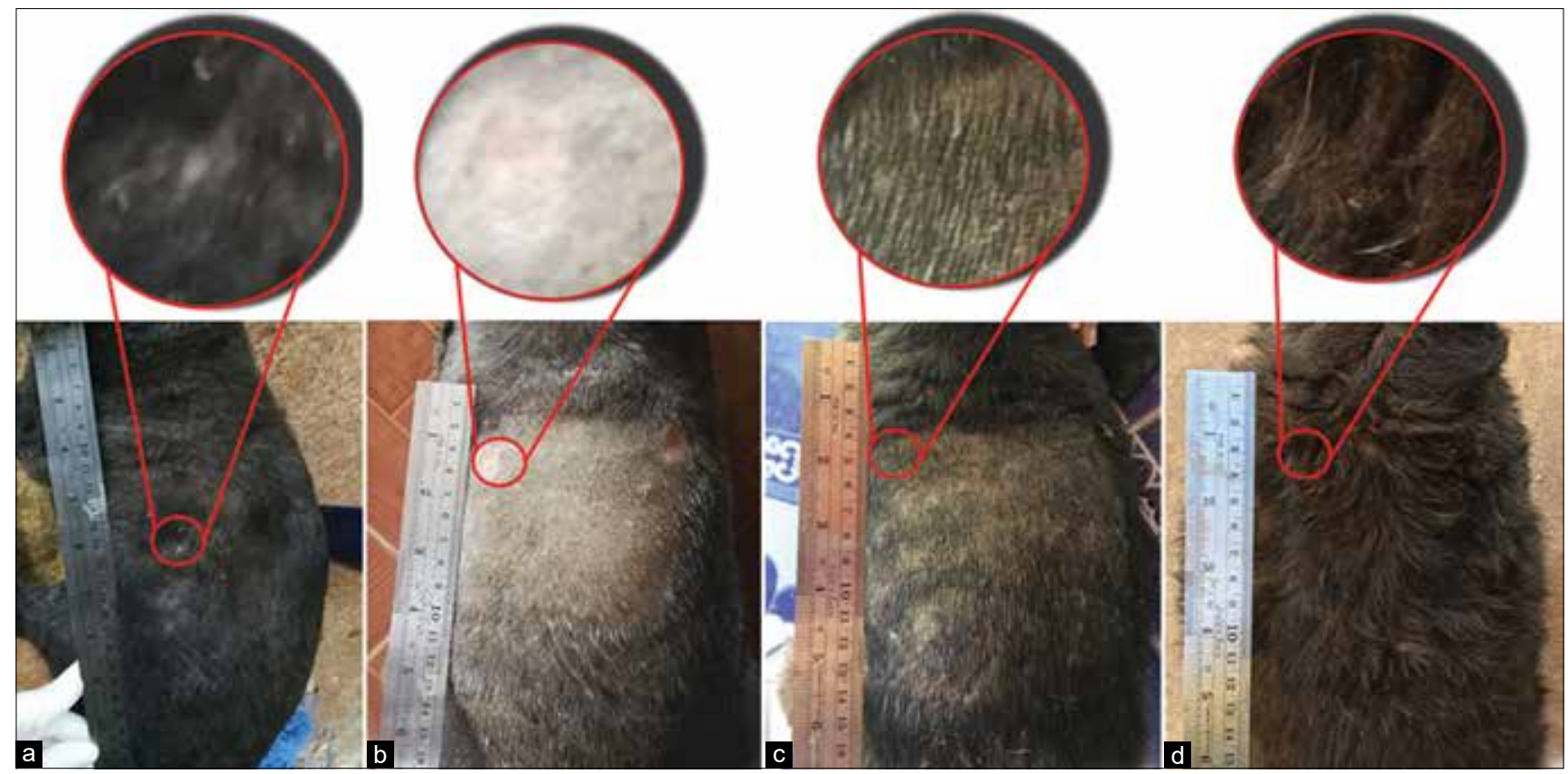

Figure-6: Occurrence of lesions in pre- and post-treatment of YN oil+MG group. Back part; pre-treatment (a), after shaving (b), 28 days post-treatment (c), and 56 days post-treatment (d).

signs (erythema, alopecia, squamae, and hyperseborrhea) disappeared at 9 weeks after treatment with honey, propolis, apple vinegar, and extracts plant [13]. In the study results of Chakraborty and Pradhan [15], dogs were treated with Teeburb capsules twice daily orally for 30 days and skin heal spray twice daily for 20-30 days. Consequently, $50 \%$ of dogs showed negative for mite infection on the $45^{\text {th }}$ day. In this study, the dogs treated with YN oil+WC showed high efficacy of clinical signs and were cured within 8 weeks.

The major component of $\mathrm{YN}$ oil is alpha-Gurjunene.Alpha-Gurjunenehas been previously reported to exhibit high antibacterial, anticancer [34], and tick-larvicidal effects [35]. WC contains rhinacanthin, which has various activities, such as anti-inflammatory [36], melanogenesis suppression [37], and antifungal activities. Finally, the major compound of MG is alpha-mangostin, which exhibits anti-inflammatory and antioxidant activities [22].

The evidence of $D$. canis infestation causing oxidative stress in dogs includes total antioxidant activity and superoxide dismutase [38]. We set out to determine the antioxidant properties of the three herbal medicines. The DPPH results of YN oil indicate no antioxidant activity, which is similar to a previous report [26]. For the other two herbs, the analysis of $\mathrm{IC}_{50}$ showed that 


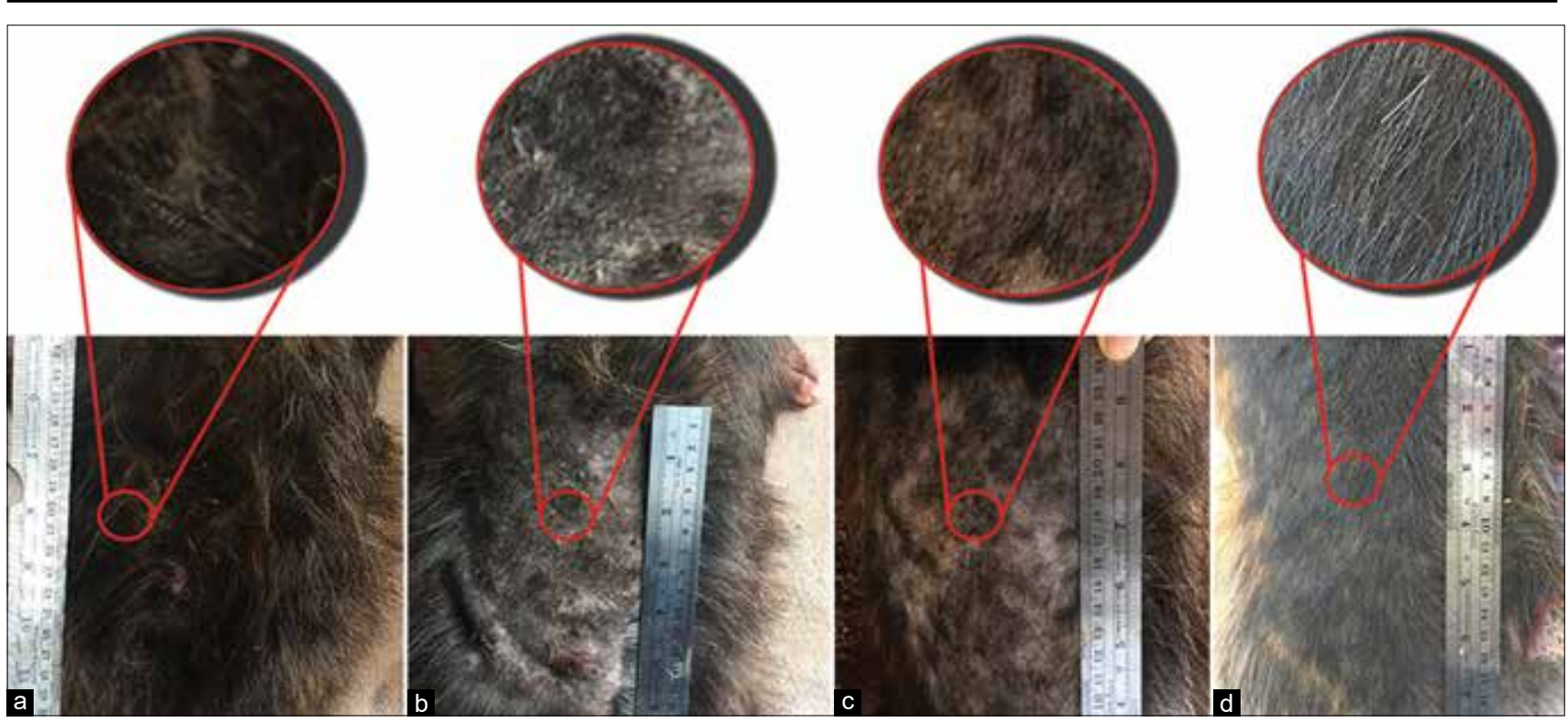

Figure-7: Occurrence of lesions in pre- and post-treatment of YN oil+WC+MG group. Back part; pre-treatment (a), after shaving (b), 28 days post-treatment (c), and 56 days post-treatment (d).

R. nasutus and G. mangostana pericarp extracts have a high antioxidant activity, which is supported by previous studies [22,39]. This could be responsible for the added benefit of adding these two herbs in this study.

A previous in vitro antifungal study showed that $13.6 \mathrm{mg} / \mathrm{mL}$ of $\mathrm{WC}$ extract exhibited inhibition of Trichophyton mentagrophytes and Microsporum gypseum until 3 days, but $27.2 \mathrm{mg} / \mathrm{mL}$ of WC showed fungicidal activity, which is similar to the previous report [40]. Thus, we prepared WC shampoo to prevent and control fungal infection during the experiment. In the present study, the dogs treated with YN oil, $\mathrm{YN}$ oil $+\mathrm{WC}, \mathrm{YN}$ oil $+\mathrm{MG}$, and $\mathrm{YN}$ oil $+\mathrm{WC}+\mathrm{MG}$ showed hair regrowth on day 56 post-treatment, which may result from the inhibition of the proliferation of the mites. The pathogenic mechanisms of alopecia in canine demodicosis are cutaneous barrier rupture by the proliferation of the mites [41]. A previously reported essential oil from Drimys brasiliensis Miers has $\alpha$-gurjunene compounds. They exhibited larvicidal activity against cattle ticks and brown dog tick [35]. Ticks are a type of Acari mite. Alphagurjunene compounds were found in $\mathrm{YN}$ oil. Hence, the mechanism of action of this compound may act on Demodex mites when considering that all dog groups treated with YN oil had regrown normal skin.

As previously reported, hyperpigmentation from canine demodicosis is caused by increasing melanocyte activity in the epidermis [42]. Our results showed that for the dogs treated with YN oil, hyperpigmentation disappeared on day 56 post-treatment. This finding is supported by a previous report that showed that sesquiterpene lactones inhibited melanin production [43]. In addition, another study found that WC extracts reduced melanogenesis [37]. This is in agreement with our results since hyperpigmentation disappeared on day 28 post-treatment in the dogs treated with YN oil+WC. When compared with dogs treated with only YN oil, the dogs' skin improved more with YN oil+WC than with only YN oil. This suggests that a combination of the YN oil and WC could highly reduce melanogenesis.

Our results showed that $\mathrm{YN}$ oil, $\mathrm{YN}$ oil+WC, and $\mathrm{YN}$ oil+WC+MG significantly decreased lichenification. Lichenification is the thickening and hardening of the skin from chronic disease. This result is in agreement with a previous report that salicylic acid solutions could produce histologic changes. The skin became thinner [44]. This result may be a consequence of the acidity of the herbal medication. All of the herb treatments were acidic with $\mathrm{pH} 5$. This $\mathrm{pH}$ may affect the epidermis of demodicosis skin, which became thinner after treatment. Furthermore, YN oil can increase skin permeability [45].

Another factor of canine demodicosis from mite infestation is nutritional conditions. Dogs with poor body conditions show higher mite infestation when compared with dogs with normal body conditions [46]. In this study, all dogs showed signs of malnutrition. Thus, we fed each dog one boiled egg every day until 30 days to boost their nutritional condition. Eggs are a high source of protein, riboflavin, and selenium, and boiled eggs are a dietary supplement for dogs.

\section{Conclusion}

In conclusion, the dermatological lesion (alopecia, hyperpigmentation, and lichenification) disappeared within 56 days in a dog treated with YN oil+WC. Our present data demonstrate that YN oil+WC can be used as an alternative treatment for localized canine demodicosis. The benefits of these herbal medications are that they are cheap and easy to find, have simple preparation, and could reduce the medication cost for treatment. No visible adverse effects were noticed from these herbal medications. 


\section{Authors' Contributions}

AA, PB, BP, PS, RA, SB, OP, and CE: Data curation, investigation, methodology, and formal analysis. AA and TB: Conceptualization and project administration. TB and WZ: Supervision and visualization. AA, PR, AS, PL, and TB: Drafted and revised the manuscript. All authors read and approved the final manuscript.

\section{Acknowledgments}

This study was financially supported by the Royal Golden Jubilee Ph.D. Programme (PHD/0168/2558), Khon Kaen University, Thailand.

\section{Competing Interests} interests.

The authors declare that they have no competing

\section{Publisher's Note}

Veterinary World remains neutral with regard to jurisdictional claims in published map and institutional affiliation.

\section{References}

1. Leydig, F. (1859) Ueber haarsackmilben and krätzmilben. Arch. Naturgeschichte, 25(1): 338-354.

2. Esenkaya, F.T. and Dik, B. (2018) A dog related Demodex spp. infestation in a student: A rare Demodex case. Mikrobiyol. Bul., 52(2): 214-220.

3. Fondati, A. (1996) Efficacy of daily oral ivermectin in the treatment of 10 cases of generalized demodicosis in adult dogs. Vet. Dermatol., 7(2): 99-104.

4. Paradis, M. and Pagé, N. (1998) Topical (pour-on) ivermectin in the treatment of chronic generalized demodicosis in dogs. Vet. Dermatol., 9(1): 55-59.

5. Kenny, P.J., Vernau, K.M. and Maggs, D.J. (2008) Retinopathy associated with ivermectin toxicosis in two dogs. J. Am. Vet. Med. Assoc., 233(2): 279-284.

6. Mealey, K.L., Bentjen, S.A., Gay, J.M. and Cantor, G.H. (2001) Ivermectin sensitivity in collies is associated with a deletion mutation of the mdr1 gene. Pharmacogenetics, 11(8): 727-733.

7. McTier, T.L., Six, R.H., Pullins, A., Chapin, S., Kryda, K., Mahabir, S.P., Woods, D.J. and Maeder, S.J. (2019) Preventive efficacy of oral moxidectin at various doses and dosage regimens against macrocyclic lactone-resistant heartworm (Dirofilaria immitis) strains in dogs. Parasit. Vectors, 12(1): 444.

8. Becker, S., Webster, A., Doyle, R.L., Martins, J.R., Reck, J. and Klafke, G.M. (2019) Resistance to deltamethrin, fipronil and ivermectin in the brown dog tick, Rhipicephalus sanguineus sensu stricto, Latreille (Acari: Ixodidae). Ticks Tick Borne Dis., 10(5): 1046-1050.

9. Currie, B.J., Harumal, P., McKinnon, M. and Walton, S.F. (2004) First documentation of in vivo and in vitro ivermectin resistance in Sarcoptes scabiei. Clin. Infect. Dis., 39(1): e8-e12.

10. Kwochka, K.W. and Kowalski, J.J. (1991) Prophylactic efficacy of four antibacterial shampoos against Staphylococcus intermedius in dogs. Am. J. Vet. Res., 52(1): 115-118.

11. Rizk, M.A., Abdalla, A.A. and El-Sayed, S.A.E. (2017) Evaluation of ascorbic acid in a combination with ivermectin in augmentation the recovery from juvenile generalized demodicosis in dogs: A randomized clinical trial. PSM vet. Res., 2(2): 14-21.

12. Hugnet, C., Lespine, A. and Alvinerie, M. (2007) Multiple oral dosing of ketoconazole increases dog exposure to ivermectin. J. Pharm. Pharm. Sci., 10(3): 311-318.

13. Mederle, N., Kaya, A., Albu Kaya, M., Pătrașcu, M., Kumbakisaka, S., Morariu, S., Gartner, A., Negrescu, A. and Dărăbuș, G. (2017) Therapeutic efficacy testing of two topical products used in dry demodicosis lesions in dogs from Mehedinti County. Lucrări Științifice, 60(2): 227-232.

14. Makwana, P., Mehta, H.K., Manisha, T., Shakkarpude, J. and Jain, A. (2015) Evaluation efficacy of herbal preparations for the treatment of canine mange. Sch. J. Agric. Vet. Sci., 2(4A): 282-284.

15. Chakraborty, S. and Pradhan, N.R. (2015) Canine demodicosis and its herbal and non-herbal treatments. Indian $J$. Can. Pract., 7(2): 115-119.

16. Chen, Y.S., Chen, C.J., Yan, W., Ge, H.M. and Kong, L.D. (2017) Anti-hyperuricemic and anti-inflammatory actions of vaticaffinol isolated from Dipterocarpus alatus in hyperuricemic mice. Chin. J. Nat. Med., 15(5): 330-340.

17. Akihisa, T., Tokuda, H., Ukiya, M., Suzuki, T., Enjo, F., Koike, K., Nikaido, T. and Nishino, H. (2004) 3-Epicabraleahydroxylactone and other triterpenoids from Camellia oil and their inhibitory effects on Epstein-Barr virus activation. Chem. Pharm. Bull., 52(1): 153-156.

18. Scholz, D., Baumann, K., Grassberger, M., WolffWiniski, B., Rihs, G., Walter, H. and Meingassner, J.G. (2004) Synthesis of dammarane-type triterpenoids with anti-inflammatory activity in vivo. Bioorg. Med. Chem. Lett., 14(11): 2983-2986.

19. Shah, M.A., Muhammad, H., Mehmood, Y., Khalil, R., Ul-Haq, Z. and Panichayupakaranant, P. (2017) Superoxide scavenging and antiglycation activity of rhinacanthins-rich extract obtained from the leaves of Rhinacanthus nasutus. Pharmacogn. Mag., 13(52): 652-658.

20. Raj, V.B.A., Kumar, K.S. and Kumar, S.S. (2015) Traditional Indian medicinal plants as a potential anti-inflammatory phytomedicine for psoriasis control. J. Pharmacogn. Phytochem., 4(3): 118-122.

21. Jaisupa, N., Moongkarndi, P., Lomarat, P., Samer, J., Tunrungtavee, V., Muangpaisan, W. and Mangmool, S. (2018) Mangosteen peel extract exhibits cellular antioxidant activity by induction of catalase and heme oxygenase-1 mRNA expression. J. Food Biochem., 42(3): e12511.

22. Aukkanimart, R., Boonmars, T., Sriraj, P., Songsri, J., Laummaunwai, P., Waraasawapati, S., Boonyarat, C., Ratanasuwan, P. and Boonjaraspinyo, S. (2015) Anthelmintic, anti-inflammatory and antioxidant effects of Garcinia mangostana extract in hamster opisthorchiasis. Exp. Parasitol., 154(7): 5-13.

23. Aukkanimart, R., Boonmars, T., Sriraj, P., Sripan, P., Songsri, J., Ratanasuwan, P., Laummaunwai, P., Boueroy, P., Khueangchaingkhwang, S., Pumhirunroj, B., Artchayasawat, A., Boonjaraspinyo, S., Wu, Z., Hahnvajanawong, C., Vaeteewoottacharn, K. and Wongkam, S. (2017) In vitro and in vivo inhibitory effects of $\alpha$-mangostin on cholangiocarcinoma cells and allografts. Asian Pac. J. Cancer Prev., 18(3): 707-713.

24. Mueller, R.S., Bensignor, E., Ferrer, L., Holm, B., Lemarie, S., Paradis, M. and Shipstone, M.A. (2012) Treatment of demodicosis in dogs: 2011 clinical practice guidelines. Vet. Dermatol., 23(2): 86-96.

25. Fourie, J.J., Meyer, L. and Thomas, E. (2019) Efficacy of topically administered fluralaner or imidacloprid/moxidectin on dogs with generalised demodicosis. Parasit. Vectors, 12: 59 .

26. Yongram, C., Sungthong, B., Puthongking, P. and Weerapreeyakul, N. (2019) Chemical composition, antioxidant and cytotoxicity activities of leaves, bark, twigs and oleo-resin of Dipterocarpus alatus. Molecules, 24(17): 3083

27. Nirmaladevi, R., Padma, P.R. and Kavitha, D. (2010) Analyses of the methanolic extract of the leaves of Rhinacanthus nasutus. J. Med. Plant Res., 4(15): 1554-1560. 28. Tunsaringkarn, T., Palanuvej, C., Issaravanich, S., 
Vipunngeun, N., Rungsiyothin, A., Chuthaputti, A. and Ruangrungsi, N. (2009) Quality assessment of Rhinacanthus nasutus. J. Health Res., 23(3): 111-115.

29. Aksoy, L., Kolay, E., Ağılönü, Y., Aslan, Z. and Kargioğlu, M. (2013) Free radical scavenging activity, total phenolic content, total antioxidant status, and total oxidant status of endemic Thermopsis turcica. Saudi J. Biol. Sci., 20(3): 235-239.

30. Hampel, V., Knaus, M., Schäfer, J., Beugnet, F. and Rehbein, S. (2018) Treatment of canine sarcoptic mange with afoxolaner $\left(\mathrm{NexGard}^{\circledR}\right)$ and afoxolaner plus milbemycin oxime (NexGard Spectra ${ }^{\circledR}$ ) chewable tablets: Efficacy under field conditions in Portugal and Germany. Parasite, 25: 63.

31. Gortel, K. (2006) Update on canine demodicosis. Vet. Clin. North Am. Small Anim. Pract., 36(1): 229-241.

32. Campbell, W.C., Fisher, M.H., Stapley, E.O., AlbersSchonberg, G. and Jacob, T.A. (1983) Ivermectin: A potent new antiparasitic agent. Science, 221(4613): 823-828.

33. Singh, S.K. and Dimri, U. (2010) Use of Withania somnifera extract in canine demodicosis. Indian Vet. J., 87(11): 1091-1092.

34. George, S., Nair, S.A., Venkataraman, R. and Baby, S. (2015) Chemical composition, antibacterial and anticancer activities of volatile oil of Melicope denhamii leaves. Nat. Prod. Res., 29(20): 1959-1962.

35. Ribeiro, V.L.S., Rolim, V., Bordignon, S., Henriques, A.T., Dorneles, G.G., Limberger, R.P. and Von Poser, G. (2008) Chemical composition and larvicidal properties of the essential oils from Drimys brasiliensis Miers (Winteraceae) on the cattle tick Rhipicephalus (Boophilus) microplus and the brown dog tick Rhipicephalus sanguineus. Parasitol. Res., 102(3): 531-535.

36. Bhusal, N., Panichayupakaranant, P. and Reanmongkol, W. (2014) In vivo analgesic and anti-inflammatory activities of a standardized Rhinacanthus nasutus leaf extract in comparison with its major active constituent rhinacanthin-C. Songklanakarin J. Sci. Technol., 36(3): 325-331.

37. Chatatikun, M., Yamauchi, T., Yamasaki, K.,
Chiabchalard, A. and Aiba, S. (2019) Phyllanthus acidus (L.) Skeels and Rhinacanthus nasutus (L.) Kurz leaf extracts suppress melanogenesis in normal human epidermal melanocytes and reconstitutive skin culture. Asian Pac. J. Trop. Med., 12(3): 98-105.

38. Martínez-Subiela, S., Bernal, L.J., Tvarijonaviciute, A., Garcia-Martinez, J.D., Tecles, F. and Cerón, J.J. (2014) Canine demodicosis: The relationship between response to treatment of generalised disease and markers for inflammation and oxidative status. Vet. Dermatol., 25(2): 72-76.

39. Suman, B., Venkata, M. and Thyagaraju, K. (2013) Phytochemical analysis, in-vitro antioxidant activity and proximate analysis on Rhinacanthus Nasutus (L) Kurz leaf. Indian J. Appl. Res., 3(5): 32-35.

40. Darah, I. and Jain, K. (2001) Efficacy of the Rhinacanthus nasutus nees leaf extract on dermatophytes with special reference to Trichophyton mentagrophytes var. mentagrophytes and Microsporum canis. Nat. Prod. Sci., 7(4): 114-119.

41. Forton, F.M.N. (2012) Papulopustular rosacea, skin immunity and Demodex: Pityriasis folliculorum as a missing link. J. Eur. Acad. Dermatol. Venereol., 26(1): 19-28.

42. Baker, K.P. (1975) Hyperpigmentation of the skin in canine demodicosis. Vet. Parasitol., 1(2): 193-197.

43. Choodej, S., Pudhom, K., Yamauchi, K. and Mitsunaga, T. (2019) Inhibition of melanin production by sesquiterpene lactones from Saussurea lappa and their analogues. Med. Chem. Res., 28(6): 857-862.

44. Imayama, S., Ueda, S. and Isoda, M. (2000) Histologic changes in the skin of hairless mice following peeling with salicylic acid. Arch. Dermatol., 136(11): 1390-1395.

45. Supawadee, D., Orawan, M., Yaowared, C. and Thanakorn, P. (2018) Development of ketoconazole shampoo with Dipterocarpus alatus oil as a permeation enhancer. Indian J. Pharm. Educ., 52(4): S197-S201.

46. Ali, M.H., Begum, N., Azam, M.G. and Roy, B.C. (2011) Prevalence and pathology of mite infestation in street dogs at Dinajpur municipality area. J. Bangladesh Agric. Univ., 9(1): 111-120. 